\title{
8
}

\section{Recycling Manhattan}

\section{Autor(es): Bem-Haja, Joana}

Publicado por: Editorial do Departamento de Arquitectura

URL persistente:

URI:http://hdl.handle.net/10316.2/37220

DOI:

DOI:http://dx.doi.org/10.14195/1647-8681_1_18

Accessed : $\quad$ 26-Apr-2023 01:32:18

A navegação consulta e descarregamento dos títulos inseridos nas Bibliotecas Digitais UC Digitalis, UC Pombalina e UC Impactum, pressupõem a aceitação plena e sem reservas dos Termos e Condições de Uso destas Bibliotecas Digitais, disponíveis em https://digitalis.uc.pt/pt-pt/termos.

Conforme exposto nos referidos Termos e Condições de Uso, o descarregamento de títulos de acesso restrito requer uma licença válida de autorização devendo o utilizador aceder ao(s) documento(s) a partir de um endereço de IP da instituição detentora da supramencionada licença.

Ao utilizador é apenas permitido o descarregamento para uso pessoal, pelo que o emprego do(s) título(s) descarregado(s) para outro fim, designadamente comercial, carece de autorização do respetivo autor ou editor da obra.

Na medida em que todas as obras da UC Digitalis se encontram protegidas pelo Código do Direito de Autor e Direitos Conexos e demais legislação aplicável, toda a cópia, parcial ou total, deste documento, nos casos em que é legalmente admitida, deverá conter ou fazer-se acompanhar por este aviso. 


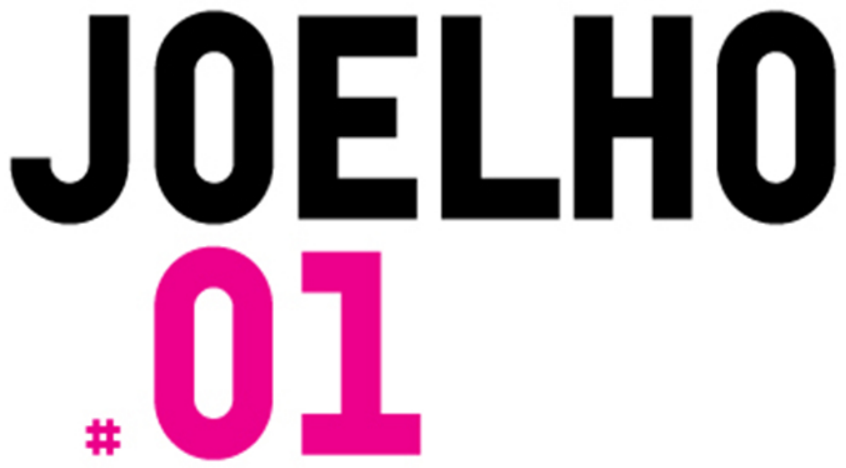

\section{MULHERES NA ARQUITECTURA}

Jorge Figueira

Coordenação

Silvana Rubino

Carla Lopes

Liliana Carvalho

Joana Bem-Haja

Filipa Cabrita

Inês Antunes

Telma Silva

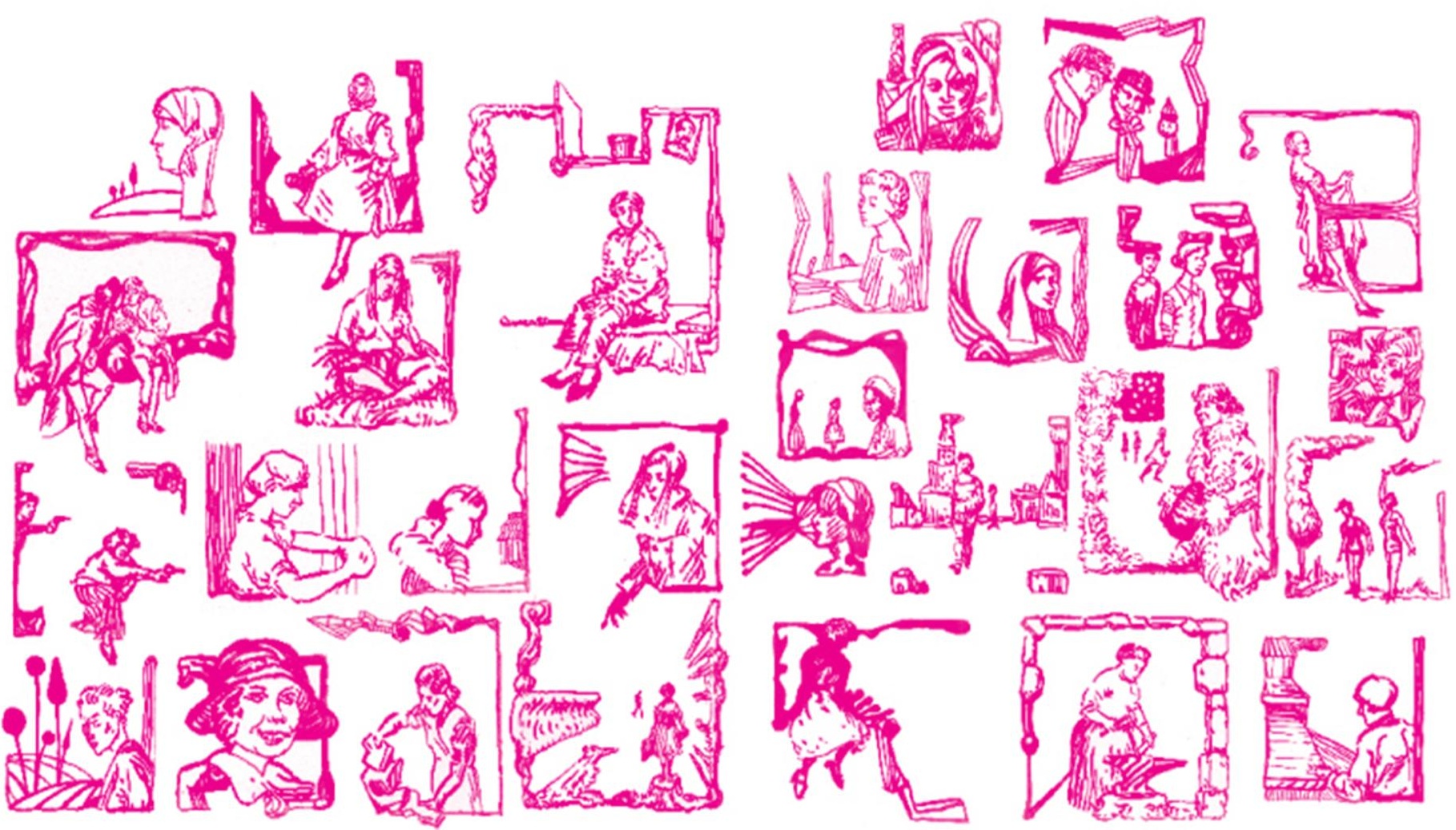




\section{Recycling \\ Manhattan}

Joana Bem-Haja

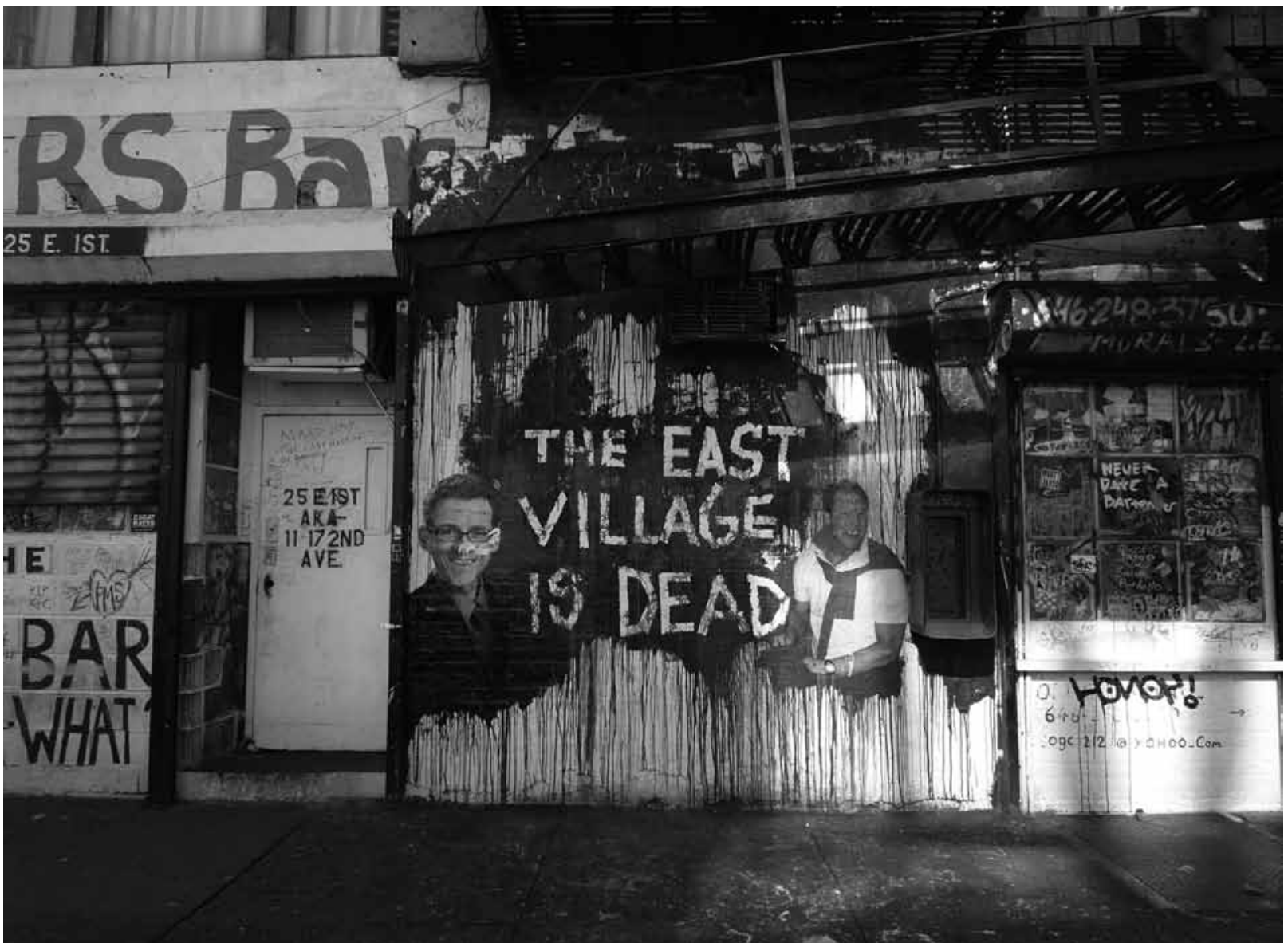

"East Village is Dead" 
À deriva pela cidade, numa das minhas incursões por Manhattan em 2008, cedo esta questão da perda da "alma" da cidade se tornou o ponto de partida do meu trabalho. $\mathrm{Na}$ tentativa de compreender a sua origem, deambulei pelas suas ruas, conversei com seus habitantes de forma a perceber se realmente e, em que medida, Nova Iorque poderia estar a perder a "sua alma", a sua identidade. Destas conversas emergem duas grandes problemáticas: o receio de perda do património histórico-cultural e a gentrificação ${ }^{2}$ que, implicando o aumento do valor do solo, dificulta a permanência dos seus actuais habitantes.

Compreendendo que um dos grandes motores de transformação urbana é o factor económico (essencialmente a indústria imobiliária), e que uma das maiores problemáticas inerentes ao desenvolvimento da cidade

I Esta questão surge igualmente como título da edição número 625, da revista Time Out New York, 2008.

2 Segundo Zukin, "Gentrification typically
occurs when a higher class of people moves into a
neighborhood, makes improvements to property that
cause market prices and tax assessments to rise, and
so drives out the previous, lower-class residents"
(Zukin, 1989 : 5). tem sido o confronto entre os interesses públicos e os privados, torna-se necessário perceber o papel e a interacção destas duas forças na constante regeneração da cidade. Assim, a metodologia adoptada incide na tentativa de identificar que mecanismos económicos, políticos, sociais e culturais têm intervindo na regeneração de Nova Iorque, de forma a melhor compreender a sua forma actual e a descobrir a origem das reivindicações dos seus habitantes. "Recycling Manhattan" é, assim, uma tentativa de compreender a cidade vivida, através do modo como esta se tem vindo a regenerar.

\section{"UPGRADING” MANHATTAN}

A vontade de acumular capital, através da especulação do solo da ilha de Manhattan, sempre acompanhou e influenciou o modo de desenvolvimento da cidade. Um dos exemplos mais emblemáticos é o loteamento do solo da ilha proposto pelo Plano de I8II que, ao dividir o solo em pequenas parcelas iguais, o torna mais rentável. Esta antiga aspiração de reestruturar o espaço urbano de Manhattan ganha forças no início do século xx. O sucesso imobiliário do desenvolvimento "delirante" do centro financeiro de Manhattan (zona de Wall Street), devido ao boom construtivo de edifícios em altura, terá sido o catalisador deste ressurgimento. Assim, nos anos I920, verificando as vantagens económicas da construção em altura e com capital investido no solo de Manhattan, surge um grupo de habitantes influentes que anseia explorar ao máximo o potencial económico do solo urbano. A sua estratégia baseava-se na expulsão da indústria e dos bairros operários de Lower Manhattan, centro industrial de Nova Iorque, para os seus subúrbios. Manhattan ficaria, assim, disponível para implementação de usos do solo mais rentáveis, a economia de serviços. 


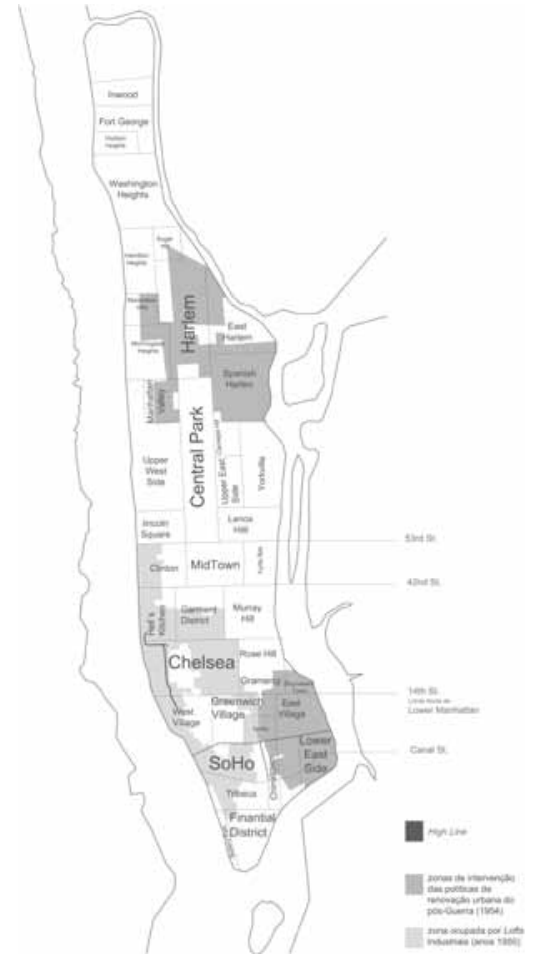

Mapa das zonas ameaçadas em Manhattan no pós-Guerra
Este desejo de transferir a indústria e a classe operária para os subúrbios era duplamente rentável. Por um lado, iria valorizar o capital investido em propriedades suburbanas, por outro, iria criar espaço no centro da cidade para novas construções de edifícios de escritórios e de habitação para classe média e alta, aumentando, assim, o lucro para os seus proprietários (Zukin, I989: 37-38). Deste grupo sobressai a família Rockefeller que, com capital investido no solo de Manhattan, decide financiar a Regional Plan Association, da qual faz parte o arquitecto Lewis Mumford, para a criação de um plano a uma escala regional, que incentive a fragmentação e expansão da cidade para as zonas circundantes. O Plano Regional de Nova Iorque é apresentado em I929, poucos meses antes do crash da Bolsa de Valores de Nova Iorque. Nesta fase, a cidade é abalada pela Grande Depressão, cuja instabilidade económica apenas permite o desenvolvimento de um amplo sistema rodoviário regional, em muito devido ao empenho de Robert Moses. Só depois da i I Guerra Mundial, nos anos I950, o desejo de reestruturar o espaço urbano se torna viável, em muito devido ao apoio político. Os incentivos à construção nos subúrbios, fomentada pelos planos federais para a habitação e pelo investimento privado da banca (sob a forma de empréstimos), a desindustrialização do centro urbano, e a implementação das políticas de renovação urbana (a cargo de Robert Moses) foram fundamentais.

Durante este período pós-Guerra, com o objectivo de "limpar" os bairros pobres, as políticas de renovação urbana de Robert Moses foram responsáveis pelo desalojamento de cerca de 500.000 habitantes $(25 \%$ do total de habitantes da ilha), e pela construção de um número aproximadamente igual de habitações (Fainstein, 2005: I-2). O grande epicentro de aplicação destes novos projectos era Lower East Side (bairro operário) e o grande alvo eram as suas características Tenement Houses. ${ }^{3}$ $\mathrm{Na}$ sua maioria, estes novos projectos baseavam-se nos ideais modernistas vigentes de integração da natureza na cidade e de descongestão de edificado, descontinuando, assim, a tão característica street wall ${ }^{4}$ de Manhattan.

Devido à imposição de profundas alterações no ecossistema urbano, estes projectos de renovação urbana começam a ser contestados pelas inúmeras e radicais alterações da paisagem edificada, da qualidade espacial e, também, da paisagem sociocultural. Estas novas políticas, ao transformarem o habitat dos actuais habitantes da ilha, relegam para segundo plano, ou mesmo ignoram, os efeitos imediatos na qualidade de vida, revelando a sobrevalorização dos interesses privados face aos interesses públicos.

Outros projectos megalómanos começam a ser amplamente criticados, dos quais se destaca a construção da via rápida Cross-Bronx (anos I950), cuja construção espalhou destruição, transformando Bronx numa zona sem habitantes, degradada. O receio da reprodução da experiência traumática da construção da Cross-Bronx e o descontentamento face às transformações radicais da paisagem urbana, destabilizadoras do ecossistema sociocultural, criam o ambiente propício para a emergência de uma contestação massiva por parte dos habitantes de Manhattan. 
Nos anos i960, os habitantes de Nova Iorque densificam a sua voz contra as políticas de renovação urbana. ${ }^{5}$ Estas políticas, ao promoverem a renovação urbana através da demolição do edificado, são as responsáveis tanto pela destruição activa de âncoras de memória dos seus habitantes, como pela ameaça de sua expulsão do centro urbano para os subúrbios. Para além da voz popular, surgem alguns arquitectos que criticam os resultados do

5 Esta contestação enquadra-se numa época marcada pela emergência de amplos movimentos sociais contestatários: contra a Guerra do Vietname, os movimentos pelos direitos civis, pela afirmação da mulher, pela igualdade racial, etc. projecto de base moderna aplicados sob o comando destas políticas, por eles consideradas atentados à vitalidade urbana e ao património histórico-cultural.

"if urban renewal is not to turn into urban devastation, which shows signs of doing, the officials of New York would well advise to take a course in the history of the city's architecture" (Ada Louise Huxtable apud Stern et al., 1996: 263).

Nesta fase de grande transformação urbana é organizada pela Universidade de Pensilvânia, em 1958, a "Conference on Urban Design Criticism”, que juntou, entre outros, Lewis Mumford, Louis Kahn, Kevin Lynch e Jane Jacobs. O seu objectivo passava por repensar as políticas de renovação urbana americanas, numa tentativa de criar projectos mais sustentáveis e humanistas. Um dos frutos desta conferência é o livro de Jane Jacobs Morte e vida das grandes cidades (2003), publicado em I96r. Após a análise do impacto causado pela aplicação das novas tipologias urbanas e arquitectónicas fomentadas pelas políticas vigentes, o argumento de Jane Jacobs constitui uma crítica bastante incisiva aos projectos de base moderna. A autora considera-os como forças opostas à vitalidade urbana e à qualidade de vida dos seus habitantes. Estes planos preordenados, monótonos, impossibilitam a diversidade urbana, segundo Jacobs, vital para o bom funcionamento do ecossistema urbano. Jacobs assume-se, assim, como uma das principais opositoras à contaminação de Manhattan pelo Movimento Moderno.

"As cidades monótonas, inertes, contêm, na verdade, as sementes da sua própria destruição e um pouco mais. Mas as cidades vivas, diversificadas e intensas contêm as sementes da sua própria regeneração" (Jacobs, 2003: 499).

O dinamismo de Jane Jacobs foi, também, decisivo no despertar da população para a contestação, na defesa do que pensam ser essencial para a sustentabilidade urbana, e produtor de qualidade de vida. Um dos exemplos mais emblemáticos foi o caso do projecto para a via-rápida LoM Ex (Lower Manhattan Expressway) de Robert Moses. Esta via-rápida pretendia rasgar a zona Sul de Manhattan, de Este a Oeste, espalhando a demolição. Devido à movimentação contestatária dos seus habitantes, dos quais se destacou Jane Jacobs, o projecto da LOM Ex não foi aprovado.

O exemplo polémico da destruição da "velha" Penn Station (I9Io), em I963, foi preponderante. Em resposta e recusando perder outra âncora de memórias, um grupo de habitantes cria, em 1965, a Comissão de Preservação dos

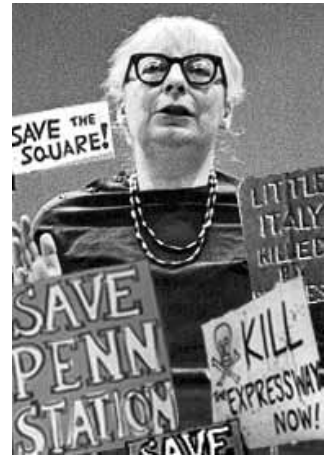

Jane Jacobs [Fotomontagem] 
Monumentos de Nova Iorque. É neste período que a cidade desperta para a noção de património. O legado de Jacobs foi, assim, crucial na emergência deste sentimento comum de preservar o edificado com valor histórico-cultural. Porém, é aqui que nasce um dos grandes perigos da vitória da preservação: a possibilidade de asfixia arquitectónica, criando barreiras a novas tipologias.

Ao despertar a voz contestatária, o legado de Jane Jacobs consciencializa a população do seu poder político no modo da cidade se reinventar, criando obstáculos aos desejos económicos de reestruturar o espaço urbano. A partir deste momento, as forças económicas viram-se sem a alavanca das políticas de renovação urbana do pós-Guerra. O destino de Lower Manhattan torna-se, assim, incerto, desorientando os seus investidores.

\section{RECYCLING SOHO}

"Throughout most of the 2oth century... SoHo was known to the city officials as 'the Valley' - a grey blur of low industrial buildings that nobody wanted to visit or look at (...)" (Koch apud Stern et al., 1995:254).

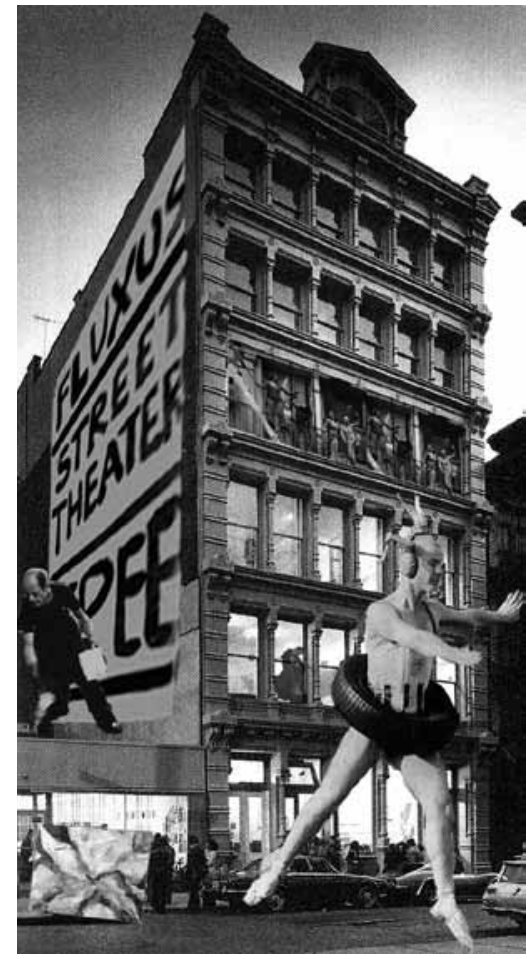

Avant-Garde artística dos anos $60 \mathrm{em}$ SoHo. [Fotomontagem]
Inesperadamente, no pós-Guerra, Nova Iorque é invadida por inúmeros artistas que procuram tanto o conforto da estabilidade económica americana, como a possibilidade de se afirmar no mundo da arte. A cidade torna-se o epicentro artístico mundial, substituindo a hegemonia parisiense. Simultaneamente, os característicos edifícios de ferro fundido do século xix, os "Cast-Iron Buildings" de SoHo (talvez a única tipologia arquitectónica originária de Manhattan), começam a ser alvo da desindustrialização, devido ao desinvestimento neste sector no pós-Guerra e à instabilidade criada pela ameaça de transformação do bairro por planos de renovação urbana.

Com um destino incerto e com os espaços armazém dos seus edifícios desocupados, os lofts, SoHo começa a ser alvo de procura por jovens artistas, tanto pelo preço praticado e pela localização (bairro contíguo de Greenwich Village, centro boémio e artístico da altura), como pelas suas características espaciais (amplos e luminosos). O espaço loft revela-se bastante apelativo para os artistas que procuravam, além de uma habitação, um lugar para trabalhar.

A invasão espontânea de SoHo por artistas torna-o, rapidamente, num vibrante epicentro de arte, num dos maiores incubadores de tendências mundiais, da avant-garde das artes plásticas, do teatro, do vídeo e da dança experimental. Contudo, o bairro continuava ameaçado, tanto pelo projecto da construção da Lomex, como pelo Plano de Lower Manhattan de $1965^{6}$. Numa tentativa de salvaguardar a sua presença na cidade e de preservar o bairro, os artistas unem-se com o intuito de mostrar à cidade e ao mundo o potencial da produção e a fruição artística de SoHo. Neste sentido, e através da SoHo Artistic Association, organizam manifestações e eventos culturais, dos quais se destacou um Festival de Arte, com a duração de três dias. Durante este evento, os lofts ocupados foram abertos e expostos ao grande público. 
No seu interior os visitantes poderiam deambular, analisar obras de arte e observar os artistas em pleno acto de criação. $O$ festival foi um êxito. Nesta altura, é também publicada uma foto-reportagem sobre o estilo de vida do artista no loft, "Living Big in Loft". O loft torna-se num objecto apetecível e SoHo assume-se como um bairro dinâmico, vivo.

Inesperadamente, este acto publicitário de SoHo tem um duplo efeito. Tanto o espaço Loft, como o estilo de vida associado ao artista começam a ser desejados por outros habitantes. Se já desde os anos I930 ou I940 que alguns artistas ocupavam lofts no anonimato, há que questionar as razões pelas quais, por volta de 1970, o Loft Living se torna uma tendência acentuada. Sharon Zukin (1989) defende que há uma alteração dos padrões de consumo, movida por uma mudança cultural profunda nos anos i960. São exemplos a emancipação dos jovens e da mulher, e consequente aumento de mulheres com carreira profissional, o aumento significativo de indivíduos com grau universitário, a proliferação da procura de alugueres para um ou dois habitantes, e a popularidade do "urban singles lifestyle" (Smith, 2002: 27I). Todas estas mudanças propiciaram a emergência de uma geração que procura habitar em bairros activos culturalmente, e/ou até boémios, atraídos pela sua dinâmica e pelo estilo de vida dos artistas. Isto origina uma nova tipologia de consumidor no mercado imobiliário, para a qual o estúdio, ou seja, o espaço loft surge como a resposta.

Além disso, nos anos i96o produz-se, pela primeira vez de uma forma generalizada, uma mudança de olhar, de apreensão dos edifícios antigos, o que revela uma profunda alteração na relação entre espaço e tempo, assim como uma busca pela autenticidade.

"Old building and old neighborhoods are authentic in a way that new construction and new communities are not. They have an identity that comes from years of continuous use and an individuality that creates a sense of place instead of space. [...] Because they are here today and tomorrow, they provide landmarks for the mind as well at the senses. In a world that changes moment by moment, anchoring the self to old is a way of coping with the continuous past" (Zukin, I989: 67-68).

O aumento da procura pelo espaço loft para habitação traz consigo os investidores imobiliários que, rapidamente, começam a reproduzir o fenómeno Loft Living, vislumbrando em SoHo a possibilidade de valorização do capital investido no solo. Surge, assim, o mercado do Loft Living, que, rapidamente, se torna num sucesso da indústria imobiliária. Entre i960 e 1970, infere-se que o número de habitantes a ocupar lofts convertidos em habitação tenha aumentado de 3.000 para 50.000 (ibidem: 6).

Em SoHo, os investidores, de uma forma perversa, aprendem que é possível valorizar um bairro previamente considerado obsoleto e sem valor, através da integração das artes (que lhe conferem dinamismo cultural) e da preservação do património histórico. Descobrem como transformar a cultura numa mercadoria, fortificando a relação entre consumo cultural e acumulação 
de capital. Porém, a consequência imediata do sucesso do Loft Living traduzse na especulação imobiliária, visível na inflação de rendas. Tal facto obriga à saída da maioria dos artistas de SoHo. Ou seja, a emergência deste mercado traz consigo o fenómeno de gentrificação.

SoHo assume-se como o ponto de viragem, o paradigma, a partir do qual a reestruturação espacial urbana define uma nova estratégia: a apropriação do património histórico e sociocultural, "reciclando-o" de forma a adaptá-lo a novos usos. Neste contexto, também a arquitectura teve de redesenhar o seu campo de acção. Como referiu Robert Stern, nos anos 1980, "Lofts are the last hope for architects" (Stern apud. Zukin, 1989: 2000).

\section{MANHATTAN, HOJE}

"The recycling of older buildings is the keystone of a new urban movement (...) a method of channelling investment back into the center city and propping up what had been until recently an altogether depressed real estate market in many cities" (Goldberger apud. Zukin, I989: 200).

A reutilização do património histórico-cultural, ao valorizar o lugar, tornou-se um negócio bastante rentável para a indústria imobiliária. A partir do exemplo paradigmático de SoHo, os investidores tentarão obter os mesmos resultados noutros bairros, segundo eles, subvalorizados. Como estratégia, estes usarão o que Zukin denomina de "Artistic Mode of Production." Enquanto em SoHo a invasão por artistas pode ser considerada espontânea,

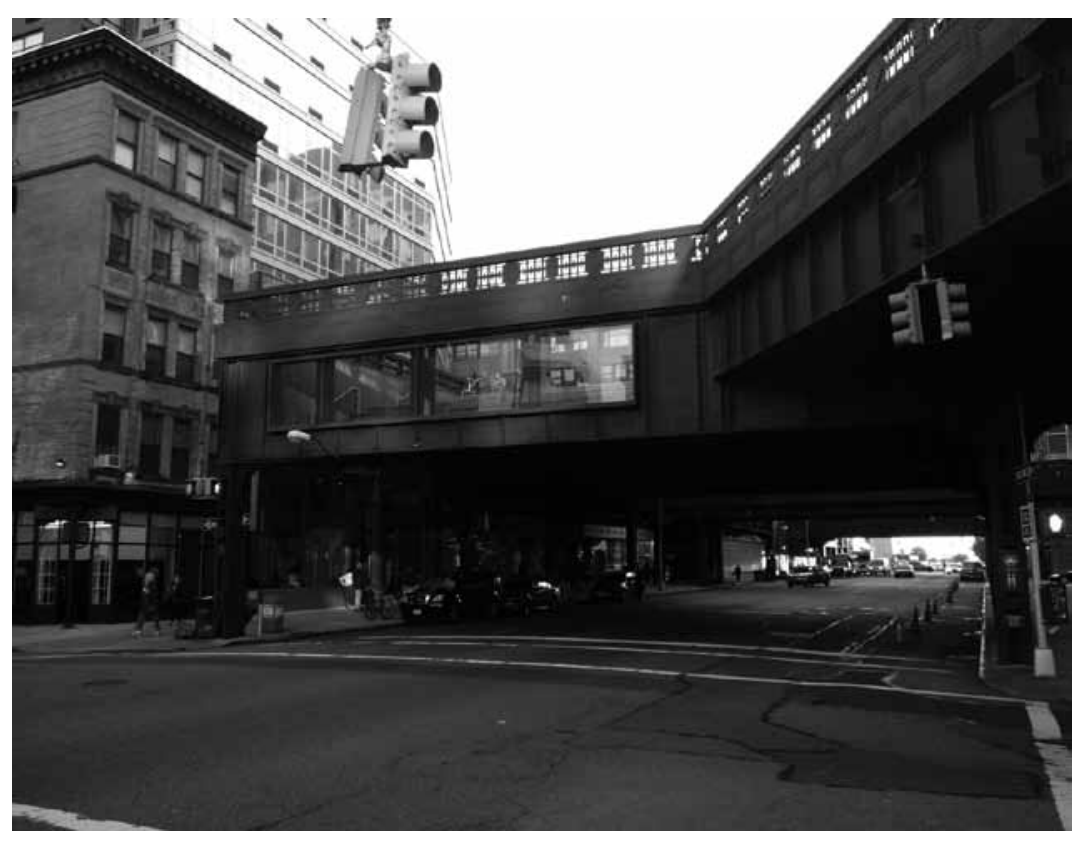

High Line 
nos próximos casos, a dinâmica cultural será induzida, tanto pela atracção de artistas, através da criação de residências artísticas ou habitação económica, como pela criação de infra-estruturas culturais. A perpetuação deste processo, através da gentrificação, culmina na tão desejada dinamização e valorização dos centros urbanos. No caso de Manhattan, a gentrificação, baseada na preservação do património histórico-cultural, manifestou os seus primeiros indícios em Greenwich Village, sedimentou-se em SoHo, e expandiu os seus tentáculos, primeiro, para East Village e, actualmente para Lower East Side e Chelsea. Neste último bairro, é amplificada pelo mediatismo em torno do projecto para construção da High Line.

\section{HIGH LINE}

No caso da High Line ${ }^{7}$ existe o desejo dos habitantes de preservar uma antiga ferrovia elevada, uma ruína pósindustrial que, após a sua desactivação nos anos i980, é alvo de várias tentativas de demolição por investidores privados, os proprietários dos terrenos trespassados pela estrutura.

7 High Line é o nome dado a uma ferrovia, elevada a cerca de 9 metros do solo, com quase 2 quilómetros e meio de extensão. Situa-se na zona Oeste de Manhattan, atravessando cerca de 22 quarteirões, trespassando o Meatpacking District, West Chelsea, e Hell's Kitchen.

Após a sua desactivação e aplicando o ensinamento de SoHo, alguns dos edifícios que interagem com a High Line, assim como os seus armazéns de apoio, localizados em Chelsea, tornam-se alvo de reinvestimento. Alguns foram ocupados por restaurantes, por espaços de diversão nocturna e por museus, contudo, a grande maioria, foi convertida em galerias de arte (David, 2002: I4). Chelsea torna-se no novo epicentro artístico de Manhattan, num
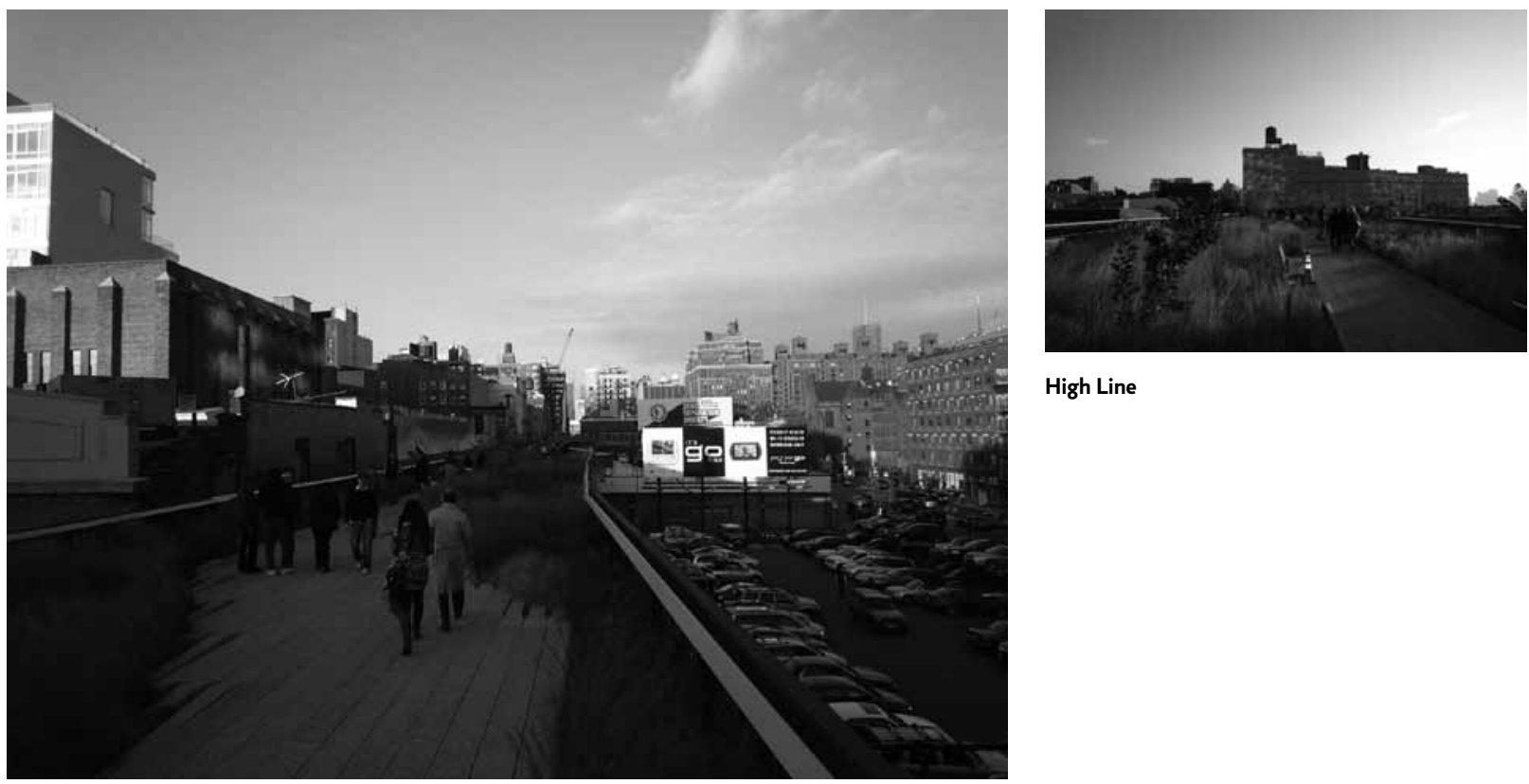

High Line 


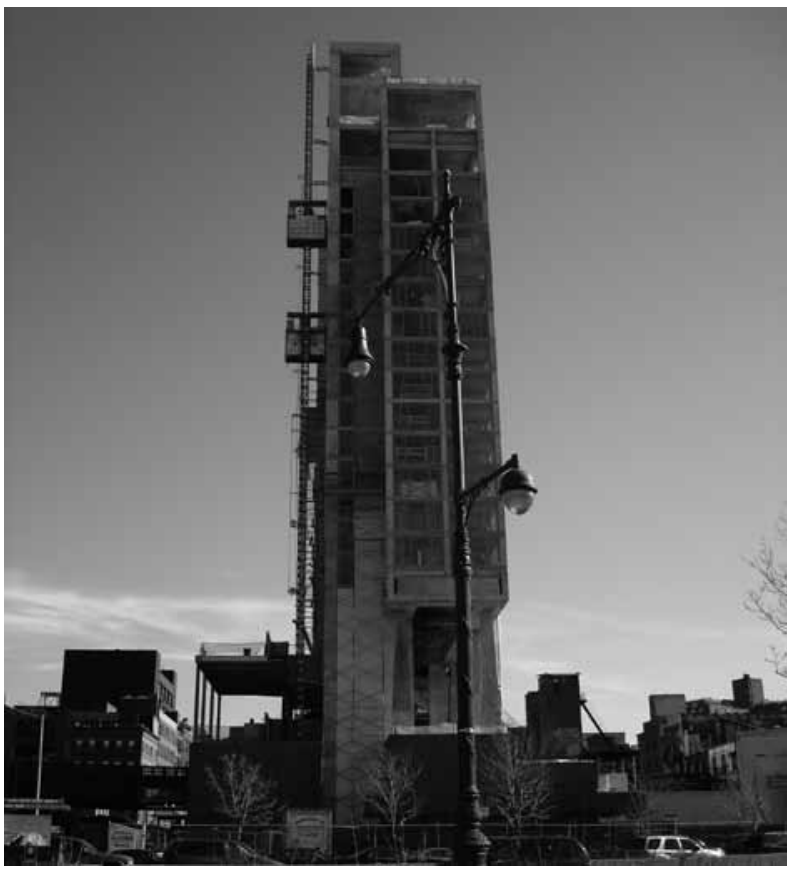

Nova Construção em torno da High Line bairro vivo. Esta apropriação artística do espaço envolvente despertou, de certo modo, para a emblemática presença da ferrovia desactivada. A High Line começou a cativar a sensibilidade dos habitantes, não só pela estrutura em si, como pelas paisagens peculiares originadas pelo seu jardim selvagem, um ecossistema rico que, espontaneamente, invadiu as suas plataformas.

Simultaneamente, o desenvolvimento artístico do bairro atrai investidores, o que, mais uma vez, põe em causa o futuro da High Line. A ferrovia torna-se o centro de diversas pressões imobiliárias e contestações. Nesse contexto, em 1999, é criado um grupo, os Amigos da High Line que, com o objectivo de proteger esta ruína pós-industrial, propõe a transformação da ferrovia num espaço lazer aberto ao público. As razões apresentadas para defender a High Line passam, tanto pela experiência paisagística única que oferece, como pelo efeito dinamizador na economia do bairro, através da atracção de capital (ibidem: I7-I9). Com o intuito de alargar o número de apoiantes para a reutilização da ferrovia, os Amigos da High Line organizaram visitas guiadas à estrutura e diversos eventos paralelos, transformando o seu desejo num verdadeiro sucesso de massas.

Entre Março e Setembro de 2004, já com o apoio do poder municipal da cidade de Nova Iorque, os Amigos da High Line criam um concurso internacional para a produção de um projecto. $\mathrm{O}$ projecto seleccionado é da criação de James Corner Field Operations (arquitectura paisagística), e de Diller Scofidio + Renfro (arquitectura), conjuntamente com horticultores, engenheiros, artistas e outros técnicos (ibidem: I7-I9). O projecto foi concebido para ocupar as plataformas segundo categorias como "natureza" e "tempo", de forma a combinar a vida vegetal e os carris já existentes com os percursos pedestres criados, através de uma estratégia que os autores definem de “agritectural”. Em Junho de 2009, a primeira secção da High Line é aberta ao público e na primeira semana recebe mais de 70.000 visitantes. Neste momento, a High Line é um ponto de referência turístico, de novas tendências, um lugar de grande dinamismo cultural.

Contudo, como se tem vindo a verificar nestes últimos anos em Manhattan, a preservação e a cultura "andam de mãos dadas" com a gentrificação. A High Line torna-se um "agente gentrificador". Inflaciona o custo do solo dos bairros circundantes e atrai investimentos imobiliários, contaminando o solo com novas construções de alta renda. Com a High Line é atingido um novo equilíbrio entre a preservação e a nova construção, sustentabilidade e gentrificação, entre interesses públicos e privados. Salva-se a ruína, mas permite-se novos projectos de condomínios de luxo à sua volta, muitos deles da autoria de arquitectos internacionais, como Jean Nouvel, Shigeru Ban e Frank Gehry, que revalorizam o lugar, globalizando-o. 


\section{LOWER EAST SIDE}

"In the century's last years there was no more dramatic story of marketdriven urban renewal than that of the transformation of the Lower East Side from one Manhattan least prosperous, least beloved neighborhoods into an ethnically diverse mecca of hipness" (Stern et al., 2006: 312).

Após várias ameaças, os primeiros sinais da gentrificação de Lower East Side surgem em meados dos anos 1990, quando ao bairro chegam artistas vindos da já gentrificada East Village. Inspirados no paradigma de SoHo e de forma a valorizar o capital investido, os proprietários de Lower East Side iniciam o controverso processo de conversão das antigas Tenement Houses em apartamentos de um só quarto.

Contemporaneamente, algumas grandes marcas internacionais mudam-se para o bairro. Acrescentando estes factos à sedutora e crescente vitalidade e fruição artística das suas ruas, uma base de sucesso é criada, na qual será possível a valorização do solo. Esta tendência mantém-se até aos dias de hoje e, progressivamente, foi alterando a identidade do bairro, confirmando a tendência em transformar o antigo bairro operário e multicultural num bairro de alta renda.

Mais uma vez a cultura se torna uma mercadoria. O bairro, ao mesmo tempo que "vende" a sua multiculturalidade, tenta assumir-se como o centro artístico da ilha. Este discurso foi, recentemente, confirmado com a construção do New Museum (2007) dos japoneses sa nAA. Simultaneamente, novos edifícios, descontextualizados com o existente, contaminam a paisagem do bairro a uma velocidade fugaz. Tais aspectos ameaçam o equilibrio so-

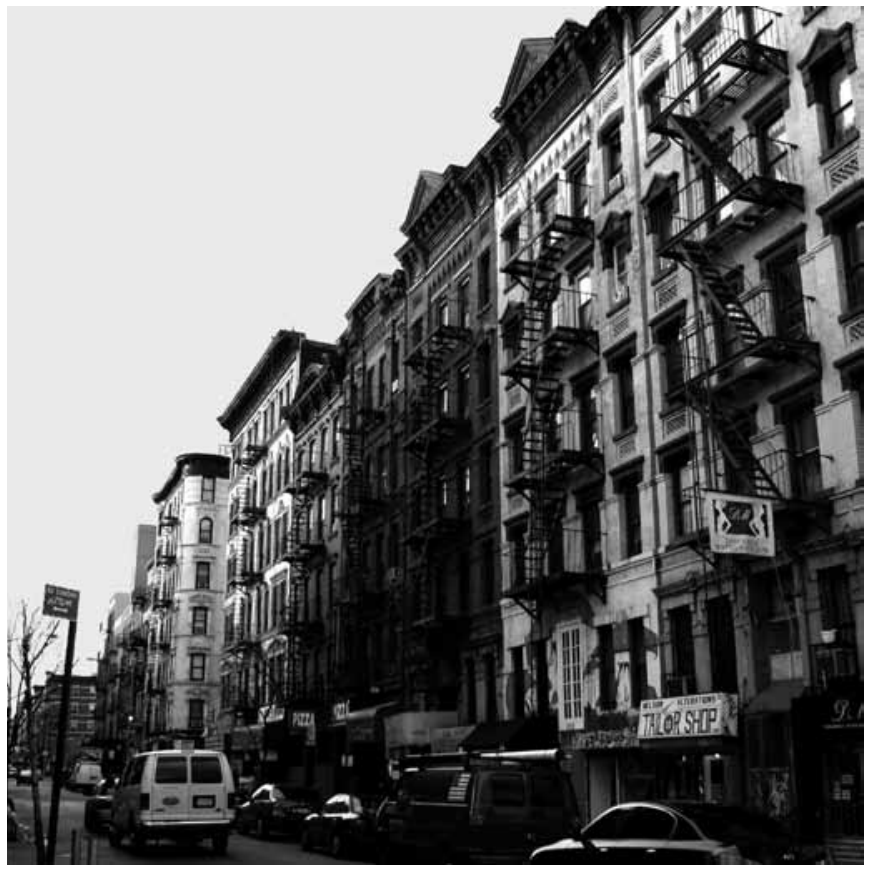

Tenement Houses, Lower East Side ciocultural do bairro, propagando o receio de gentrificação total de Lower East Side, já pressentida pelo aumento de rendas, que em alguns casos atinge os $300 \%$ assim como, o medo de transformação da paisagem edificada do bairro.

Neste contexto, emergem grupos de habitantes organizados que, tentando travar os últimos desenvolvimentos do seu bairro, propõem ao Departamento de Planeamento de Nova Iorque a alteração do zoneamento deste. Em 2008, depois de três anos de debate intenso entre o Departamento e os representantes eleitos pela população, a alteração do zoneamento foi aprovada. Sendo assim, é incentivada a construção de habitação economicamente acessível através do programa Inclusionary Housing. ${ }^{8}$ Um novo limite máximo de altura é estabelecido, assim como a obrigatoriedade de construção de edifícios em sintonia com contexto arquitectónico do bairro. Esta alteração de zoneamento tem efeitos imediatos. Actualmente existe uma tendência de estabilização do mercado imobiliário em Lower East Side.

8 O programa Inclusionary Housing, criado para comunidades economicamente integradas em áreas que sofrem de grande desenvolvimento construtivo, oferece pisos bónus, relativamente ao limite do zoneamento da zona em questão, a projectos que incluam habitação mais económica. (New York City, 2009b) 
O facto de estas reivindicações terem resultado no incentivo do governo municipal à construção de habitação económica, comprova que as forças políticas estão a despertar, ainda que lentamente, para esta problemática da segregação social. Entretanto, basta saber que outras soluções surgirão. A integração da opinião pública na fase de concepção do projecto poderá ser uma das soluções, na tentativa de um urbanismo mais comunitário, mais justo, porque mais democrático.

\section{CONCLUSÃO}

Recycling Manhattan é, então, uma estratégia através da qual a regeneração de Manhattan encontrou um novo equilíbrio entre os interesses públicos e os privados. Sob influência de forças económicas vorazes, reciclar tornou-se a ponte possível entre o desejo público de preservação do património histórico-cultural e o desejo privado de acumulação de capital. Tanto o caso de Lower East Side como o da High Line evidenciam uma forte relação entre consumo cultural e acumulação de capital, no modo da cidade se reinventar, revelando a sua inspiração nos ensinamentos do desenvolvimento paradigmático de SoHo. A gentrificação e activismo comunitário afirmam-se como mecanismos de regeneração urbana recorrentes que permitem a preservação do património histórico-cultural, o perpetuar da herança das mudanças socioculturais dos anos i96o. Reabilitar torna-se, assim, a palavra-chave na regeneração de Nova Iorque após os anos r970.

Mais do que preservar, as forças motrizes de desenvolvimento tentam produzir realidades de consumo, segundo os modelos da sociedade em que estão inseridos. É neste contexto, que a construção simbólica de progresso se reinventa num desejo comum de preservar. Neste processo, reutilizar o edificado urbano é o campo no qual a arquitectura se terá de reinventar. Será através da arquitectura que se tornará visível a adaptação, das forças motrizes de desenvolvimento, aos novos modelos de consumo.

É neste sentido que o fenómeno do Loft Living se apresenta como um processo social de construção de uma paisagem pós-moderna, processo que, como refere Zukin, "depende de uma fragmentação económica das antigas solidariedades urbanas e de uma reintegração que está fortemente alterada pelos novos modos de apropriação cultural” (Zukin, I996: 205).

Esta ambiguidade criada pela paisagem pós-moderna, na qual os lugares se desligam de uma lógica capitalista industrial e incorporam novos usos, novos padrões de consumo disfarçados por detrás de paisagens "cast-iron" ou "brownstone", como em Manhattan, cria o que Zukin denomina de "espaços liminares pós-modernos”. Os espaços liminares, são então, espaços que "tanto falseiam como fazem a mediação entre natureza e artefacto, uso público e valor privado, mercado global e lugar específico" (Ibidem: 205). Reciclar, preservando o edificado, é, portanto, criar "espaços liminares pós-modernos". Contudo, o sucesso no mercado imobiliário que estes espaços liminares costumam obter, tem como consequência a erosão da identidade que permitiu 
a sua própria existência. A imagem, que impulsionou a atracção pelo lugar, permanece enquanto imagem que o vende. Ironicamente, é esta imagem apropriada, a responsável pela expulsão dos indivíduos que a construíram, pela destruição da identidade original do lugar. Ou seja, o acto de reciclar o edificado redefine o significado de lugar. É neste sentido que os seus habitantes contestam a perda da "alma" da cidade.

Se, no inicio do século xx, Nova Iorque solidificou o seu percurso global como cidade "delirante" com o ímpeto da construção simbólica do novo Mundo, do progresso, desde os anos I970, em certa medida, uma nuvem de sobriedade invadiu a cidade que, depois da construção do fantástico, se tornou mais introspectiva, dedicando-se à reutilização do seu edificado. À alma da cidade, hoje, foi incorporada uma nova característica, a da preservação. É esta possibilidade de adaptar o edificado aos usos contemporâneos, de "reciclar Manhattan”, que nos permite, no século xxi, chegar a Manhattan e deambular por entre as suas ruas como se de uma viagem no tempo se tratasse.

\section{Referências bibliográficas}

Berman, Marshall (1989), Tudo o que é sólido se dissolve no ar. Lisboa: Edições 70.

David, Joshua (2002), Reclaiming the High Line [Em Linha]. New York: Design Trust for Public Spaces. Disponivel em www.designtrust.org/ pubs/01_Reclaiming_High_Line.pdf. [Consult. 6 Dez. 2008].

-

Fainstein, Susan S. - The return of urban renewal. Harvard Design Magazine [Em linha]. 22 (Spring / Summer 2005).. Disponível em www.gsd.harvard. edu/research/publications/hdm/back/22_Fainstein. pdf. [Consult. 1 Junho 2009]

一

Jacobs, Jane (2003), Morte e vida de grandes cidades. São Paulo: Martins Fontes.

-

Koolhaas, Rem (1994), Delirious New York. New York: Monacelli Press.

-

New York City (2009a). New York City Government. Department of city planning - East Village / Lower East Side: Overview [Em linha]. Disponível em www. nyc.gov/html/dcp/html/evles/index.shtml.[Consult. 10 Agosto 2009].

-

New York City (2009b). New York City

Government. Department of city planning - Zoning reference. [Em linha]. Disponível em www.nyc. gov/html/dcp/html/zone/zh_inclu_housing.shtml. [Consult. 14 Abril 2009].
Smith, Neil (2008), Gentrification, the frontier, and the restructuring of urban space. In CAMPBELL, Scott; FAINSTEIN, Susan S., ed. - Readings in urban theory. Malden: Blackwell Publishing. [2 ${ }^{\mathrm{a}}$ ed., reimpressa].

Smith, Neil (1996) The new urban frontier: gentrification and the revanchist city. London : Routledge.

\section{-}

Stern, Robert A. M.; FISHMAN, David; TILOVE, Jacob (2006), New York 2000: architecture and urbanism between the bicentennial and the millennium. New York: The Monacelli Press.

Stern, Robert A. M.; MELLINS, Thomas; FISHMAN, David (1995), New York 1960: architecture and urbanism between the Second World War and the bicentennial. New York: The Monacelli Press.

The High Line (2009), Design team selection. [Em Linha] Disponivel em www.thehighline.org/design/ design-team-selection2009. [Consult. 27 Julho 2009]. -

Zukin, Sharon (1989), Loft living, culture and capital in urban change. London: Rutgers University Press.

Zukin, Sharon (1996), Paisagens pós-modernas: mapeando cultura e poder. Revista do Património Histórico e Artístico Nacional [Em linha]. 24, 205219. Disponivel em www.iphan.gov.br/revistadopatrimonio/index.htm. [Consult. 29 Abril 2009].

\section{Créditos das imagens}

"East Village is Dead". [Arquivo de Ricardo Seiça, 2009].

-

Mapa das zonas ameaçadas em Manhattan no pósGuerra. [Joana Bem-Haja, 2009].

Jane Jacobs. [Fotomontagem Joana Bem-Haja, 2009].

-

Avant-Garde artística dos anos 60 em SoHo.

[Fotomontagem Joana Bem-Haja, 2009].

High Line. [Arquivo de Ricardo Seiça, 2009].

High Line. [Arquivo de Ricardo Seiça, 2009].

-

High Line. [Arquivo de Ricardo Seiça, 2009].

-

Nova Construção em torno da High Line [Arquivo de Joana Bem-Haja, 2008].

-

Tenement Houses, Lower East Side [Arquivo de Joana Bem-Haja, 2008].

-

Nova Construção e as Tenement Houses, Lower East Side [Arquivo de Joana Bem-Haja, 2008]. 